\title{
Elit Hentbol Oyuncularında Omuz İzokinetik Kuvveti ile Top Atış Hızı Arasındaki İlişkinin İncelenmesi
}

\author{
Aykut DÜNDAR ${ }^{1}$, Zait Burak AKTUĞ $^{2 *}$, Fatih MURATHAN ${ }^{3}$ \\ ${ }^{1}$ Adlyaman Üniversitesi, BESYO, Adlyaman, https://orcid.org/0000-0002-1012-1274 \\ ${ }^{2}$ Niğde Ömer Halisdemir Üniversitesi, BESYO, Niğde, https://orcid.org/0000-0002-5102-4331 \\ ${ }^{3}$ Adlyaman Üniversitesi, BESYO, Adlyaman, https://orcid.org/0000-0001-8887-4463
}

ÖZ

$\mathrm{Bu}$ çalışma elit hentbol oyuncularında omuz izokinetik kuvveti ile top atış hızı arasındaki ilişkiyi araştırmak amacıyla yapılmıştır. Çalışmaya hentbol süper liginde mücadele eden 13 gönüllü erkek hentbolcu katılmıştır. Hentbolcuların izokinetik omuz internal (IRPT) ve eksternal (ERPT) rotasyon peak torklar1 $\left(60^{\circ} \mathrm{s}^{-1}, 240^{\circ} \mathrm{s}^{-1}\right.$ ve $\left.400^{\circ} \mathrm{s}^{-1}\right)$ izokinetik dinamotre ile durarak ve hareketli top atış hızları ise radar cihazı ile belirlenmiştir. Hentbolcuların izokinetik omuz kuvveti ile top atış hızı arasındaki ilişkiyi belirlemek için Spearman Korelasyon Analizi kullanılmıştır. Yapılan istatistiksel analiz sonucunda IRTP $\left(60^{\circ} \mathrm{s}^{-1}, 240^{\circ} \mathrm{s}^{-1}\right.$ ve $\left.400^{\circ} \mathrm{s}^{-1}\right)$ ile durarak top atış hızı arasında ve IRPT $\left(240^{\circ} \mathrm{s}^{-1}\right)$ ile hareketli şekilde top atış hızı arasında pozitif yönde anlamlı bir ilişki bulunmuştur. Sonuç olarak hentbolda yoğun olarak kullanılan üst ekstremite kuvveti ile sporcuların bireysel ve takım performanslarına doğrudan etkisi olan top atış hızı arasında pozitif doğrultuda anlamlı bir ilişki tespit edilmiştir. Özellikle antrenörlerin antrenman içeriklerinde internal rotasyonda top atış hızını etkileyen internal rotatör kasların (M. Subscapularis, M. Delteiod Aterior, Pectoralis Major vb.) kuvvetlendirilmesine yönelik çalışmalara yer vermeleri önerilebilir.

Orijinal Makale
Yayın Bilgisi
Gönderi Tarihi: 19.10 .2018
Kabul Tarihi: 21.12 .2018
Online Yayın Tarihi: 31.12 .2018

DOI: 10.30769/usbd.472514

Anahtar kelimeler:

Hentbol,

omuz izokinetik kuvveti,

top atış hızı

\section{The Investigation of the Relationship Between Shoulder Izokinetic Strength and Ball Shoot Velocity in Elite Handball Players}

\begin{abstract}
This study was conducted to investigate the relationship between isokinetic strength and ball shoot velocity in elite handball players. Thirteen voluntary male handball players, who were playing in the handball super league, participated in the study. The isokinetic shoulder internal (IRPT) and external (ERPT) rotation peak torques $\left(60^{\circ} \mathrm{s}^{-1}, 240^{\circ} \mathrm{s}^{-1}\right.$ and $400^{\circ} \mathrm{s}^{-1}$ ) of the handball players' by isokinetic dynamotres, their ball shooting velocitys were determined by radar device. Spearman Correlation Analysis was utilized to determine the relationship between isokinetic shoulder strength and ball shooting velocity. As a result of the statistical analysis, it has been found that there is a positive relationship between a IRTP $\left(60^{\circ} \mathrm{s}^{-1}, 240^{\circ} \mathrm{s}^{-1}\right.$ and $\left.400^{\circ} \mathrm{s}^{-1}\right)$ and the ball shooting velocity while not moving and IRPT $\left(240^{\circ} \mathrm{s}-1\right)$ and the ball shooting velocity while moving. As a result, significant relationship has been detected between the upper extremity strength used in handball and ball shooting velocity which has a direct effect on the individual and team performance of the athletes. In particular, coaches may be advised to include tranining on the strengthening of internal rotator muscles (M. Subscapularis, M. Delteiod Aterior, Pectoralis Major etc.) affecting ball velocity during internal rotation.
\end{abstract} Original Article 


\section{GíRiş}

Hentbol, dünya genelinde yaklaşık 18 milyon sporcusu olan ve 150 den fazla uluslararası federasyonu bulunan, gelişimi devam eden, uluslararası organizasyonlarda büyük bir öneme sahip takım sporudur (Gorostiaga ve ark., 2006). Hentbol, oyun kurallarında yapılan bazı değişiklikler ile birlikte oldukça hızlı oynanan bir oyun haline gelmiştir. Bu değişikliklerin sonucunda oyundaki hız artışına sporcuların uyum sağlayabilmesi için performanslarının üst düzeyde olması gerekmektedir. Hentbol oyununun performans belirleyicilerinde dayanıklılık, sürat, çeviklik, beceri, hareketlilik, sıçrama, çabuk kuvvet, kuvvette devamlılığa ilaveten top atış hızını etkileyen kuvvet özelliklerine ihtiyaç duyulur (Aguilar ve ark., 2012; Eler ve Bereket, 2001; Gorostiaga ve ark., 2006; Granados ve ark., 2013; Hermassi ve ark., 2010).

Sporcu atış yapmak için hazır olduğunda ayak bileği ve el bilek eklemleri de dahil olmak üzere bütün vücut bölümlerini kullanması gerekmektedir. Vücut uygun bir şekilde koordine olduğunda, proksimal üyelerde oluşan enerjiyi distal üyelere aktarma becerisi artarak yüksek bir hıza ulaşır (Sommervoll, 2005).

Hentbolde atış anında kinematik zincirde sırasıyla omuz, dirsek, el bileği eklemleri ve topun maksimal hıza ulaştığı görülmüştür (Joris ve ark., 1985; Kotzamanidis ve ark., 1995). Atış hızı, sporcunun kuvvet üretebilme becerisi ile yakından ilişkilidir. Kuvvet artışı, kasılma hızını ve atış anında topa uygulanan kuvvet miktarını belirler (Gorostiaga ve ark., 2006; Chu, 1998; Marques ve ark., 2007). Çoğunlukla, hentbolde atış hızı, maksimum pelvis, gövde ve omuz internal rotasyon hizından etkilenir (Wagner ve ark., 2010; Wagner ve ark., 2011). Literatür incelendiğinde bazı çalışmalarda kuvvet antrenmanları neticesinde atış hızının anlamlı düzeyde arttığı sonucu bulunmuştur (Chelly ve ark., 2010; Hermassi ve ark., 2010; Hermassi ve ark., 2011).

Yapılan çalışmanın amacı, elit düzeydeki hentbolcuların izokinetik omuz kuvveti ile hareketli ve durarak top atış hızları arasındaki ilişkinin incelenmesidir.

\section{YÖNTEM}

\section{Çalışma Grubu}

Çalışmaya Türkiye Hentbol Süper Liginde oynayan 13 erkek hentbolcu gönüllü olarak katılmıştır. Çalışmaya katılan hentbolcuların omuz eklemine ait son 6 ay içerisinde herhangi bir yaralanma geçirmemiş olmasına dikkat edilmiştir. Ölçümler başlamadan önce hentbolculara ölçümlerle ilgili bilgilendirme yapılmıştır.

\section{Veri Toplama Aracı}

\section{İzokinetik kuvvet ölçümü}

Çalışmaya katılan hentbolcuların izokinetik kas kuvvetleri Biodex marka izokinetik dinamometre (Biodex 3 Pro Medical System NY, Shirley) ile spor hekimleri tarafindan 
ölçülmüştür. Kuvvet ölçümlerinden önce her bir sporcuya bireysel olarak mümkün olduğunca standart bir 1sınma protokolü uygulanmıştır (10-15 dk). Isınma programları içerisinde hentbolcular kol ergometresi ve germe egzersizleri ile çalıştırılmıştır. Isınma sonrası hentbolcular ölçüme teker teker alınmış, bireysel antropometrik özelliklerine göre cihazın ayarlamaları yapılmıştır. Hentbolcuların $60^{\circ} \mathrm{s}^{-1}, 240^{\circ} \mathrm{s}^{-1}$ ve $400^{\circ} \mathrm{s}^{-1}$ açısal hızlarda iç (IR) ve dış rotasyon (ER) konsantrik izokinetik kuvvetleri belirlenmiştir. Ölçümler $60^{\circ} \mathrm{s}^{-1}$ açısal hızda 5 tekrar, $240^{\circ} \mathrm{s}^{-1}$ ve $400^{\circ} \mathrm{s}^{-1}$ açısal hızlarda ise 10 tekrardan oluşmuştur. Ölçümler her iki omuza da uygulanmış, her açısal hız arasında $60 \mathrm{sn}$, her iki omuz arasında $3 \mathrm{dk}$ dinlenme verilmiştir.

\section{Top atış hızı ölçümü}

Çalışmaya katılan hentbolcuların top atış hızları Stalker Solo2 (Plano, USA) marka radar aleti ile belirlenmiştir. Hentbolcuların top atış hızları dominant (D) ve nondominant (ND) kolla durarak ve hareketli olarak ayrı ayrı yapılmıştır. Hentbolculardan uygulayabilecekleri en yüksek hızla atış yapmaları istenmiş, her sporcuya 3 tekrar yaptırılarak en iyi skor çalışmaya dahil edilmiştir.

\section{Verilerin Analizi}

Elde edilen veriler SPSS 24,0 programı kullanılarak analiz edilmiştir. Verilerin değerlendirilmesinde tanımlayıcı istatistik olarak en büyük değer, en küçük değer, aritmetik ortalama ve standart sapma kullanılmıştır. İzokinetik omuz kuvveti ile top atış hızı arasındaki ilişki Spearman korelasyon analizi ile belirlenmiştir. Çalışmada anlamlılık düzeyi $\mathrm{p}<0.05$ olarak kabul edilmiştir.

\section{BULGULAR}

Tablo 1. Hentbolcuların fiziksel özellikleri

\begin{tabular}{lcccc}
\hline & N & Min & Mak & Orta \pm Ss \\
\hline Yaş (yıl) & 13 & 20 & 29 & $24.36 \pm 5.12$ \\
Boy $(\mathrm{cm})$ & 13 & 170 & 200 & $188.85 \pm 7.09$ \\
Vücut Ağırlı̆̆ $(\mathrm{kg})$ & 13 & 63 & 110 & $92.61 \pm 12.02$ \\
VKİ $\left(\mathrm{kg} / \mathrm{m}^{2}\right)$ & 13 & 21.8 & 28.9 & $25.85 \pm 2.08$ \\
\hline
\end{tabular}

Çalışmaya katılan hentbolcuların yaş ortalamaları 24,36 $\pm 5,12$ yıl, vücut ağırlıkları ortalamalar1 92,61 $\pm 12,02 \mathrm{~kg}$, boy uzunlukları ortalamalar1 $188.85 \pm 7.09 \mathrm{~cm}$, VKİ ortalamalar1 $25,85 \pm 2,08 \mathrm{~kg} / \mathrm{m}^{2}$ ' dir. 
Tablo 2. Hentbolcuların durarak ve hareketli top atış hızları

\begin{tabular}{lcccc}
\hline$(\mathrm{km} / \mathrm{s})$ & N & Min & Mak & Orta \pm Ss \\
\hline D DŞH & 13 & 56.1 & 95.3 & $78.3 \pm 12.8$ \\
ND DŞH & 13 & 53.2 & 94.8 & $68.34 \pm 14.21$ \\
D HŞH & 13 & 49.8 & 104.8 & $85.0 \pm 16.39$ \\
ND HŞH & 13 & 50.4 & 100.1 & $73.65 \pm 15.66$ \\
\hline
\end{tabular}

$\mathrm{DSSH}=$ Durarak şut hızı $\quad \mathrm{HSSH}=$ Hareketli şut hızı $\quad \mathrm{D}=$ Dominant $\quad \mathrm{ND}=\quad$ Nondominant

Çalışmaya katılan hentbolcuların dominant kol durarak şut hızı ortalamaları 78,3 $\pm 12,8 \mathrm{~km} / \mathrm{s}$, nondominant kol durarak şut hızı ortalamaları $68,34 \pm 14,21 \mathrm{~km} / \mathrm{s}$, dominant kol hareketli şut hızı ortalamaları $85,0 \pm 16,39 \mathrm{~km} / \mathrm{s}$, nondominant kol hareketli şut hızı ortalamaları 73,65 $\pm 15,66$ $\mathrm{km} / \mathrm{s}^{\prime} \mathrm{dir}$.

Tablo 3. Dominant ve nondominant omuz eksternal ve internal rotasyon peak torkları

\begin{tabular}{|c|c|c|c|c|}
\hline$(\mathrm{Nm})$ & $\mathbf{N}$ & Min & Mak & $\operatorname{Orta} \pm$ Ss \\
\hline $\mathrm{D} \mathrm{IRPT}_{60}{ }^{\circ} \mathrm{s}^{-1}$ & 13 & 98.2 & 259.3 & $178.75 \pm 53.95$ \\
\hline $\mathrm{DERPT}_{60}{ }^{\circ} \mathrm{s}^{-1}$ & 13 & 55.8 & 130.4 & $99.9 \pm 24.86$ \\
\hline $\mathrm{D} \mathrm{IRPT}_{240^{\circ}} \mathrm{s}^{-1}$ & 13 & 113.4 & 260.8 & $159.53 \pm 38.91$ \\
\hline $\mathrm{D} \mathrm{ERPT}_{240}{ }^{\circ} \mathrm{s}^{-1}$ & 13 & 50.5 & 125.2 & $94.1 \pm 27.3$ \\
\hline $\operatorname{D~IRPT}_{400}{ }^{\circ} \mathrm{s}^{-1}$ & 13 & 114 & 294.2 & $169.09 \pm 46.12$ \\
\hline $\mathrm{D} \mathrm{ERPT}_{400} \mathrm{o}^{\mathrm{s}} \mathrm{s}^{-1}$ & 13 & 42.3 & 168.7 & $96.75 \pm 33.5$ \\
\hline $\mathrm{ND}^{\prime R P T}{ }_{60}{ }^{\circ} \mathrm{s}^{-1}$ & 13 & 92 & 232.9 & $164.84 \pm 40.47$ \\
\hline $\mathrm{ND} \mathrm{ERPT}_{60}{ }^{\circ} \mathrm{s}^{-1}$ & 13 & 74.9 & 167.3 & $120.83 \pm 16.63$ \\
\hline $\mathrm{ND} \mathrm{IRPT}_{240} \mathrm{~S}^{-1}$ & 13 & 103.4 & 247.8 & $151.54 \pm 36.69$ \\
\hline $\mathrm{ND} \mathrm{ERPT}_{240^{\circ}} \mathrm{s}^{-1}$ & 13 & 15 & 150.7 & $104.79 \pm 25.04$ \\
\hline $\mathrm{ND} \mathrm{IRPT}_{400}{ }^{\circ} \mathrm{s}^{-1}$ & 13 & 123.3 & 214.5 & $154.42 \pm 25.45$ \\
\hline $\mathrm{ND} \mathrm{ERPT}_{400} \mathrm{~S}^{-1}$ & 13 & 72.6 & 161 & $110.95 \pm 22.58$ \\
\hline
\end{tabular}

ERPT $=$ Eksternal rotasyon peak tork $\quad$ IRPT $=$ İnternal rotasyon peak tork

$\mathrm{D}=$ Dominant $\quad \mathrm{ND}=$ Nondominant $\quad \mathrm{Nm}=$ Newton metre

Çalışmaya katılan hentbolcuların D IRPT ${ }_{60}{ }^{\circ} \mathrm{s}-1$ ortalamaları $178,75 \pm 53,95 \mathrm{Nm}, \mathrm{D} \mathrm{ERPT}_{60}{ }^{\circ} \mathrm{s}-1$ ortalamalar1 $99,9 \pm 24,86 \mathrm{Nm}, \mathrm{D}$ IRPT $_{240^{\circ} \mathrm{s}-1}$ ortalamalar1 $159,53 \pm 38,91 \mathrm{Nm}, \mathrm{D} \mathrm{ERPT}_{240^{\circ} \mathrm{s}-1}$ ortalamalar1 $94,1 \pm 27,3 \mathrm{Nm}, \mathrm{D}$ IRPT $_{400^{\circ} \mathrm{s}-1}$ ortalamalar1 $169,09 \pm 46,12 \mathrm{Nm}, \mathrm{D} \mathrm{ERPT}_{400^{\circ} \mathrm{s}-1}$ ortalamalar1 $96,75 \pm 33,5 \mathrm{Nm}, \mathrm{ND}_{\text {IRPT }} 0^{\circ} \mathrm{s}-1$ ortalamalar1 $164,84 \pm 40,47 \mathrm{Nm}, \mathrm{ND}_{\mathrm{ERPT}} 0^{\circ} \mathrm{s}-1$ ortalamalar1 $120,83 \pm 16,63 \mathrm{Nm}, \mathrm{ND}$ IRPT $_{240^{\circ} \mathrm{s}-1}$ ortalamalar1 $151,54 \pm 36,69 \mathrm{Nm}, \mathrm{ND}$ $\mathrm{ERPT}_{240^{\circ} \mathrm{s}-1}$ ortalamalar1 $104,79 \pm 25,04 \mathrm{Nm}, \mathrm{ND}$ IRPT $_{400}{ }^{\circ} \mathrm{s}-1$ ortalamalar1 $154,42 \pm 25,45 \mathrm{Nm}$, ND ERPT $400^{\circ}$ s-1 ortalamaları $110,95 \pm 22,58 \mathrm{Nm}$ 'dir. 
Tablo 4. Dominant kol top atış hızları ile dominant omuz eksternal ve internal rotasyon peak torkları arasındaki ilişki değerleri

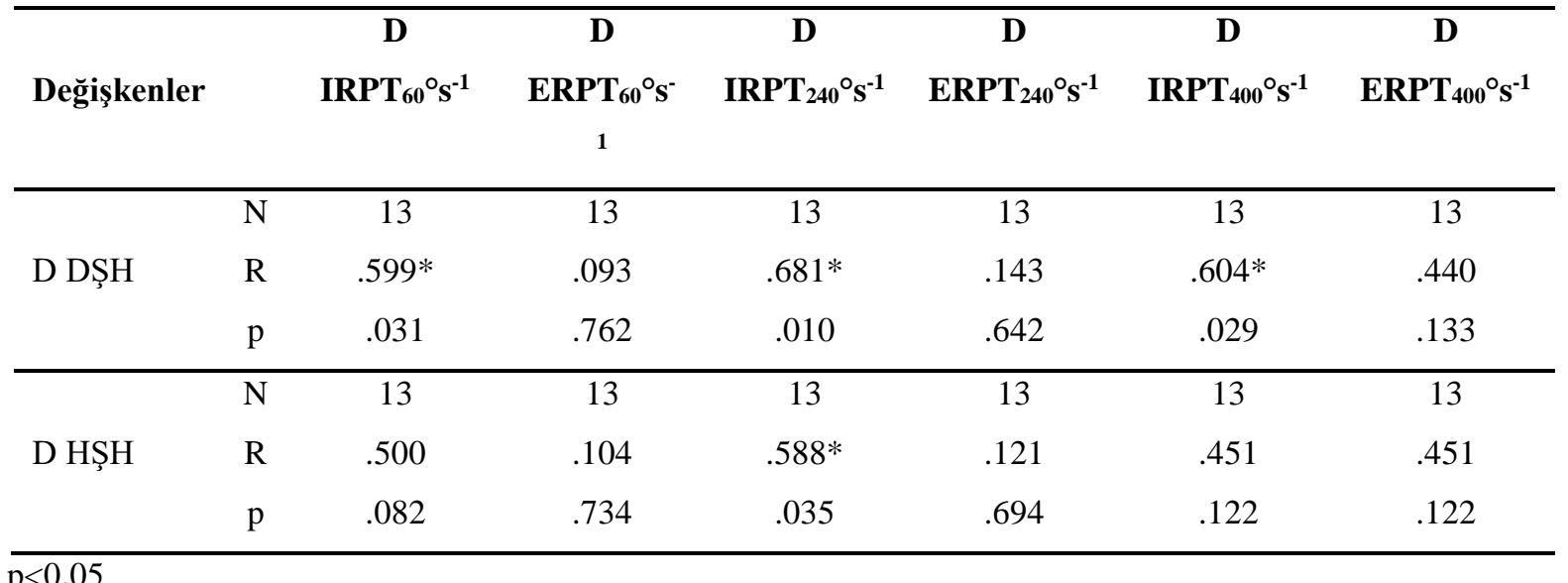

ERPT $=$ Eksternal rotasyon peak tork $\quad$ IRPT $=$ İnternel rotasyon peak tork

$\mathrm{DŞH}=$ Durarak şut hızı $\quad \mathrm{HŞH}=$ Hareketli şut hızı $\quad \mathrm{D}=$ Dominant $\quad \mathrm{ND}=$ Nondominant

Tablo 4 incelendiğinde hentbolcuların D kol DŞH ile $60^{\circ} \mathrm{s}^{-1}$ IRPT, $240^{\circ} \mathrm{s}^{-1}$ IRPT ve $400^{\circ} \mathrm{s}^{-1}$ IRPT arasında, D kol HŞH ile $240^{\circ} \mathrm{s}^{-1}$ IRPT arasında pozitif yönlü anlamlı ilişki belirlenmiştir.

Tablo 5. Nondominant kol top atış hızları ile nondominant omuz ERPT ve IRPT arasındaki ilişki

\begin{tabular}{|c|c|c|c|c|c|c|c|}
\hline \multicolumn{2}{|l|}{ Değişkenler } & ND & ND & ND & ND & ND & ND \\
\hline & & $\operatorname{IRPT}_{60}{ }^{\circ} \mathrm{s}^{-1}$ & $\operatorname{ERPT}_{60}{ }^{\circ} \mathbf{s}^{-1}$ & IRPT $_{240^{\circ}} \mathrm{s}^{-1}$ & $\mathrm{ERPT}_{240^{\circ}} \mathrm{s}^{-1}$ & IRPT $_{400}{ }^{\circ} \mathrm{s}^{-1}$ & ERPT $_{400}{ }^{\circ} \mathrm{S}^{-1}$ \\
\hline \multirow{3}{*}{ ND DŞH } & $\bar{N}$ & 13 & 13 & 13 & 13 & 13 & 13 \\
\hline & $\mathrm{R}$ & -.115 & -.038 & -.066 & -.214 & .033 & .478. \\
\hline & $\mathrm{p}$ & .707 & .901 & .831 & .482 & .915 & .098 \\
\hline \multirow{3}{*}{ ND HŞH } & $\mathrm{N}$ & 13 & 13 & 13 & 13 & 13 & 13 \\
\hline & $\mathrm{R}$ & -.011 & .077 & -.132 & -.154 & -.071 & .516 \\
\hline & $\mathrm{p}$ & .972 & .803 & .668 & .616. & .817 & .071 \\
\hline
\end{tabular}

$\mathrm{p}<0.05$

ERPT $=$ Eksternal rotasyon peak tork $\quad$ IRPT $=$ İnternel rotasyon peak tork

$\mathrm{DŞH}=$ Durarak şut hızı $\quad \mathrm{HSSH}=$ Hareketli şut hızı $\quad \mathrm{D}=$ Dominant $\quad \mathrm{ND}=$ Nondominant

Tablo 5 incelendiğinde ND kol DŞH ve HŞH ile omuz ERPT ve IRPT arasında anlamlı bir ilişki tespit edilmemiştir.

\section{TARTIŞMA VE SONUÇ}

Yapılan çalışmada hentbolcuların D omuz IRPT $\left(60^{\circ} \mathrm{s}^{-1}, 240^{\circ} \mathrm{s}^{-1}\right.$ ve $\left.400^{\circ} \mathrm{s}^{-1}\right)$ ile DŞH arasında ve D omuz IRPT $\left(240^{\circ} \mathrm{s}^{-1}\right)$ ile HŞH arasında istatistiksel olarak pozitif yönlü anlamlı bir ilişki belirlenmiştir. 
Benzer bir çalışmada 6 haftalık sağlık topu firlatma egzersizlerinin hentbolcularda omuz izokinetik kuvvetini ve atış hızını anlamlı ölçüde arttırdığı sonucu bulunmuştur (Raeder ve ark., 2015). Genç hentbolcular üzerinde yapılan bir başka çalışmada 4 haftalık kuvvet antrenmanları sonucunda durarak ve hareketli top atış hızlarında belirgin bir artış tespit edilmiştir (Sabido ve ark., 2016). Gençoğlu ve arkadaşlarının (2011) yaptığı çalışmada hentbolculara uygulanan pliometrik kuvvet antrenmanlarının omuz kuvvetini geliştirdiğini ve buna bağlı olarak durarak ve hareketli atış hızlarının arttığını belirlemiştir. Hoff ve Almåsbakk (1995) yaptıkları çalışmada 9 haftalık maksimal kuvvet antrenmanlarının atış hızı ve kas kuvvetine etkisini incelemiş, sonuç olarak hentbolcuların hem durarak hem de hareketli top atış hızlarını arttırdığını tespit etmiştir. Başka bir çalışmada Bayios ve arkadaşları (2001) hentbolcuların izokinetik omuz kuvvetleri ile top atış hızları arasındaki ilişkiyi incelemiş, kuvvet ile top atış hızının birbirine paralel olarak arttığını belirlemiştir. Gorostiaga ve arkadaşları (2006) hentbolcuların müsabaka sezonu sonunda durarak ve hareketli atış hızlarının anlamlı bir şekilde arttığını belirtmiştir. Ayrıca literatürde omuz kuvvetinin hentbolde top atış hızını anlamlı derecede arttırdı̆̆ı sonucunu gösteren başka çalışmalarda bulunmaktadır (Gorostiaga ve ark., 1999; Marques ve Gonzalez, 2006; Schwesig ve ark., 2016).

Yukarıda belirtilen çalışmalar çalışmamızın sonuçlarını destekler nitelikte olup, IRPT artmasının top atış hızını geliştirdiğini belirtmektedir. Çalışmamızın sonucunda tespit edilen DŞH ile omuz IRPT arasındaki pozitif ilişki, hentboldaki temel atış tekniği ile internal rotasyonun birbirine benzer hareketler olmasından kaynaklanabilir. Ayrica bu durum hentbolcuların internal rotasyon esnasındaki kuvvet yüksekliğinin topun itiş hızını etkilemesi ile ilgili olabilir.

$\mathrm{HSSH}$ ile $60^{\circ} \mathrm{s}^{-1}$ ve $400^{\circ} \mathrm{s}^{-1}$ açısal hızlarda IRPT arasında anlamlı ilişki çıkmaması ise hareketli atış tekniğinde el bileği, dirsek, gövde ve alt ekstremite gibi değişkenlerin kuvvetlerinin de hareketin yapılışında etkin olması ile açıklanabilir.

Hentbolcuların omuz ERPT ile top atış hızı arasında anlamlı bir ilişki bulunmamıştır. Bu durumun hentbol atış tekniğinde hareketin ilk aşamasında kolun geriye doğru salınımı sırasında kuvvete daha az gereksinim duyulmasından kaynaklanabileceği düşünülmektedir.

Ayrıca çalışmamızda ND omuz IRPT ve ERPT ile top atış hızı arasında anlamlı bir ilişki bulunmamaktadır. $\mathrm{Bu}$ durum hentbolcuların dominant kollarını kullanmalarına bağlı, nondominant kollarının kuvvet eksikliğinden kaynaklı olabilir. Tablo 3 incelendiğinde hentbolda özellikle atış hızı ile ilişkili olan IRPT'larının nondominant omuzda dominant omuza göre daha düşük olması düşüncemizi destekler niteliktedir.

Sonuç olarak, omuz izokinetik kuvveti ve atış hızı arasındaki anlamlı ilişkiden hareketle hentbolda sonuca etki eden faktörlerden biri olan atış hızının geliştirilmesinde, sporcuların üst ekstremiteye yönelik kuvvet çalışmaları yapmaları ve özellikle internal rotasyon kuvvetlerini geliştirmeleri gerektiği söylenebilir. 


\section{KAYNAKLAR}

Aguilar-Martinez, D., Chirosa, L.J., Martin, I., Chirosa, I.J., \& Cuadrado-Reyes, J. (2012). The effect of strength training on throwing velocity in team handball. Revista Internacional de Medicina y Ciencias de la Actividad Fisica y del Deporte, 12(48), 729-744.

Bayios, I.A., Anastasopoulou, E.M., Sioudris, D.S., \& Boudolos, K.D. (2001). Relationship between isokinetic strength of the internal and external shoulder rotators and ball velocity in team handball. The Journal of Sports Medicine Physical Fitness, 41(2), 229-235.

Chelly, M.S., Hermassi, S., \& Shephard, R.J. (2010). Relationships between power and strength of the upper and lower limb muscles and throwing velocity in male handball players. Journal of Strength and Condition Research, 24(6), 1480-1487.

Chu, D.A (1998). Jumping into Plyometrics. 2nd ed. Champaign, IL, Human Kinetics, p. 1-7.

Eler, S., Bereket, S. (2001). Elit Türk ve yabancı hentbolcuların motorik ve fizyolojik parametrelerinin karşılaştırılması, Gazi Üniversitesi Beden Eğitimi ve Spor Bilimleri Dergisi, 6(4), 46-48.

Gençoğlu, C., Ateş, O., Aksu, İ., Gülbahar, S., Şahin, E., \& Bediz, C. (2011). Üst ekstremite pliyometrik antrenmanın hentbolda atış hızı ve omuz rotator kas kuvvetine etkisi, Spor Hekimliği Dergisi, 46(2), $57-66$.

Granados, C., Izquierdo, M., Ibanez, J., Ruesta, M., \& Gorostiaga, E.M. (2013). Are there any differences in physical fitness and throwing velocity between national and international elite female handball players?. Journal of Strength and Condition Research, 27(3), 723-732.

Gorostiaga, E.M., Granados, C., Ibanez, J., Gonzalez-Badillo, J.J., \& Izquierdo, M. (2006). Effects of an entire season on physical fitness changes in elite male handball players. Medicine \& Science in Sports \& Exercise, 38(2), 357-366.

Gorostiaga, E.M., Izquierdo, M., Iturralde, P., Ruesta, M., \& Ibáñez, J. (1999). Effects of heavy resistance training on maximal and explosive force production, endurance and serum hormones in adolescent handball players. European Journal of Applied Physiology and Occupational Physiology, 80(5), 485493.

Hermassi, S., Chelly, M.S., Tabka, Z., Shephard, R.J., \& Chamari, K. (2011). Effects of 8-week in-season upper and lower limb heavy resistance training on the peak power, throwing velocity, and sprint performance of elite male handball players. Journal of Strength and Condition Research, 25(9), 2424-2433.

Hermassi, S., Chelly, M.S., Fathloun, M., \& Shephard, R.J. (2010). The effect of heavy- vs. moderate-load training on the development of strength, power, and throwing ball velocity in male handball players. Journal of Strength and Condition Research, 224(9), 2408-2418.

Hoff, J., \& Almåsbakk, B. (1995). The effects of maximum strength training on throwing velocity and muscle strength in female team-handball players. The Journal of Strength \& Conditioning Research, 9(4), 255-258.

Jöris, H.J.J., Van Muyen, A.E., van Ingen Schenau, G.J., \& Kemper, H. C. G. (1985). Force, velocity and energy flow during the overarm throw in female handball players. Journal of Biomechanics, 18(6), 409-414.

Kotzamanidis, C., Karahekaglas, A., Kiparos, A., Giavroglov, A., \& Tsaarouhas, E. (1995). The relationship between the physical and strength variables of the lower limbs and the velocity of ball release in various types of handball throws. European Handball, 2, 25-30.

Marques, M.A.C., ve González-Badillo, J. J. (2006). In-season resistance training and detraining in professional team handball players. Journal of Strength and Conditioning Research, 20(3), 563-571. 
Marques, M,C., van den Tillaar, R., Vescovi, J.D., \& Gonzalez Badillo, J. J. (2007). Relationship between throwing velocity, muscle power, and bar velocity during bench press in elite handball players. International Journal of Sports Physiology and Performance, 2(4), 414-422.

Raeder, C., Fernandez,-Fernandez, J., \& Ferrauti, A. (2015). Effects of six weeks of medicine ball training on throwing velocity, throwing precision, and isokinetic strength of shoulder rotators in female handball players. Journal of Strength and Conditioning Research, 29(7), 1904-1914.

Sabido, R., Hernández-Davó, J.L., Botella, J., Moya, M. (2016). Effects of 4-week training intervention with unknown loads on power output performance and throwing velocity in junior team handball players. PLOS ONE, 11(6): e0157648 2016.

Schwesig, R., Hermassi, S., Wagner, H., Fischer, D., Fieseler, G., Molitor, T., \& Delank, K. S. (2016). Relationship between the range of motion and isometric strength of elbow and shoulder joints and ball velocity in women team handball players. Journal of Strength and Condition Research, 30(12), 3428-3435.

Sommervoll, Y. (2005). Effect of gender and traning experience on kinematical and temporal aspect of overarm throwing technique. Master Thesis, Norwegian University Human Movement Science, Faculty of Social Sciences and Eechnology Management, Norway

Wagner, H., Buchecker, M., von Duvillard, S.P., \& Muller, E. (2010). Kinematic description of elite vs. low level players in team-handball jump throw. Journal of Sports Sciences and Medicine, 9(1), 15-23.

Wagner, H., Pfusterschmied, J., von Duvillard, S., \& Muller, E. (2011). Performance and kinematics of various throwing techniques in team-handball. Journal of Sports Sciences and Medicine, 10(1), 73-80. 